\title{
Validity of Qualis database as a predictor of evidence hierarchy and risk of bias in randomized controlled trials - a case study in dentistry
}

\author{
Christiane Alves Ferreira, Carlos Alfredo Salles Loureiro, Humberto Saconato, Alvaro Atallah \\ Medicina - UNIFESP, Universidade Federal de São Paulo, São Paulo, SP, Brazil.
}

\begin{abstract}
OBJECTIVE: To evaluate the validity of the Qualis database in identifying the levels of scientific evidence and the
\end{abstract} quality of randomized controlled trials indexed in the Lilacs database.

METHODS: We selected 40 open-access journals and performed a page-by-page hand search, to identify published articles according to the type of study during a period of six years. Classification of studies was performed by independent reviewers assessed for their reliability. Randomized controlled trials were identified for separate evaluation of risk of bias using four dimensions: generation of allocation sequence, allocation concealment, blinding, and incomplete outcome data. The Qualis classification was considered to be the outcome variable. The statistical tests used included Kappa, Spearman's correlation, Kendall-tau and ordinal regressions.

RESULTS: Studies with low levels of scientific evidence received similar Qualis classifications when compared to studies with high levels of evidence. In addition, randomized controlled trials with a high risk of bias for the generation of allocation sequences and allocation concealment were more likely to be published in journals with higher Qualis levels.

DISCUSSION: The hierarchy level of the scientific evidence as classified by type of research design, as well as by the validity of studies according to the bias control level, was not correlated or associated with Qualis stratification.

CONCLUSION: Qualis classifications for journals are not an approximate or indirect predictor of the validity of randomized controlled trials published in these journals and are therefore not a legitimate or appropriate indicator of the validity of randomized controlled trials.

KEYWORDS: Databases; Bibliographic; Randomized controlled trial; Bias; Validity; Empirical assessment.

Ferreira CA, Loureiro CAS, Saconato H, Atallah A. Validity of Qualis database as a predictor of evidence hierarchy and risk of bias in randomized controlled trials - a case study in dentistry. Clinics. 2010;66(2):337-342.

Received for publication on September 27, 2010; First review completed on October 19, 2010; Accepted for publication November 11, 2010

E-mail: chrisaf2005@gmail.com

Tel.: $55313047-1714$

\section{INTRODUCTION}

Since 1996, the Coordination of Higher Education Personnel Training (Capes) has been investing great efforts in qualifying Brazilian scientific production, thus resulting in the publication of the Qualis database. Qualis' initial proposal was to subsidize the assessment of Brazilian scientific publications, but this original proposal has been extrapolated. Today, the results of the assessment have served as a tool to aid in funding concessions, in the inclusion of book titles within libraries and indexes, to guide researchers and readers when choosing titles for the submission of their work or when researching relevant bibliographic materials, to encourage editors to raise the

Copyright (C) 2010 CLINICS - This is an Open Access article distributed under the terms of the Creative Commons Attribution Non-Commercial License (http:// creativecommons.org/licenses/by-nc/3.0/) which permits unrestricted noncommercial use, distribution, and reproduction in any medium, provided the original work is properly cited. quality standards considered in assessments of works for publication in an attempt to maintain funding, among other relevant circumstances ${ }^{1}$.

Until recently, the Qualis database had used a classification system based on two dimensions: the data base in which the journal was indexed and the impact factor of the journal, which was measured according to the citations received by published articles. As of 2008, the Qualis database has been altered, changing the original classification to a scale of eight strata, divided into A1, A2, B1, B2, B3, $\mathrm{B} 4, \mathrm{~B} 5$, and $\mathrm{C}^{2-3}$.

The Qualis database uses the impact factor, a bibliometric indicator that measures the frequency of citations from scientific production. For classification, Qualis uses the impact factor as a basis, reproducing the main methodological limitations of the impact factor, which include: the absence of citation quality assessment, the inclusion of auto-citations, an analysis centered around publications in English ${ }^{4-5}$. Upon consulting a group of editors in psychology journals, Costa $^{6}$ observed that the main complaint form researchers and 
authors about Qualis was referent to the absence of qualitative appreciation of the journals and the content of their articles.

The Lilacs database presents a considerable number of articles that assess the Qualis database, but no study has effectively tested, in practice, the correlation between Qualis and the strength of scientific evidence or internal validity of the studies. The majority of studies that have assessed the Qualis database have used biliometric quality markers, norms of the journals or studies, and indexing rules ${ }^{7-8}$. These items do not represent empirical evidence concerning study effect modifiers.

Thus, the objective of the present study is to verify if, despite the criticism of the Qualis database, there in fact exists a correlation between Qualis and the hierarchy of scientific evidence, as well as between Qualis and the risk of bias.

\section{MATERIAL AND METHODS}

Forty dentistry journals, listed in the Lilacs database with an open access through the Virtual Health Library (VHL), were selected. Next, a page-by-page handsearch ${ }^{9}$ was carried out in the selected journals to identify and analyze the articles. All articles published in the assessed journals were classified. A time window of six years (2002, 2003, 2004, 2005, 2006, 2007) was set.

The reason for justifying the inclusion of regional databases is the ability to reduce publication bias, database, location and country. The reduction of such biases increases the internal and external validity of the answers to clinical questions, including the effects of interventions mediated by the regional context, and provides the best evidence to support decision-making processes of planners, managers, providers of health services ${ }^{10}$.The relevance of the LILACS database was evaluated in several studies. Systematic reviews to evaluate the medical, Clark $^{11}$ concluded that the LILACS is generally underused and unpublished indexes articles of good quality and for this reason should be included routinely in search strategies for performing RS. Manríquez ${ }^{12}$ conducted a study in the field of dermatology and found that there were unpublished studies in LILACS not recoverable in other databases. Freitas ${ }^{13}$ however, found that for the physical therapy area, had a very small number of RCT, with moderate to high quality published in Spanish or Portuguese, but were difficult to located.

The choice of this time period was due to the time necessary for the published articles to have a chance to be cited by authors from systematic or listed revision from other databases, such as the CENTRAL (Cochrane library), aimed at a future cohort study.

The classification regarding the study type was carried out by two independent reviewers (CAF and HS). Disagreements were discussed until a consensus had been reached. The degree of agreement between the reviewers was measured using the Kappa statistical method, employing a sample of 380 articles (1\% error and $99 \%$ confidence interval). The test result was considered to be satisfactory (kappa $=0.85)$. For the assessment of the risk of bias from the studies considered to be potential randomized controlled trials (RCT), two independent reviewers (CAF and CAL) classified each of the studies in such a way as to assure that these judgments could be reproduced. The degree of agreement between the reviewers was once again measured by the Kappa statistical method, and the result was considered to be satisfactory (Kappa $=0.89)$.

The concepts used to classify the studies by study type were based on Rothman ${ }^{14}$ - Manual for reviewers and glossary of Cochrane Collaboration terms ${ }^{10}$

The hierarchy of evidence of studies was set according to the scale proposed by the "Oxford Centre for Evidencebased Medicine Levels of Evidence" ${ }^{\prime 15}$, classifying from the lowest to the highest level of evidence, with some adaptations, in the following manner: laboratory studies (in vitro or animal research) (evidence level of 1); narrative reviews and case series or case reports (evidence level of 2); crosssectional or descriptive studies (evidence level of 3); casecontrol study (evidence level of 4); cohort study (evidence level of 5); controlled clinical trials - CCT (evidence level of 6); RCT (evidence level of 7); systematic revisions (SR) with or without meta-analysis (evidence level of 8).

To assess the risk of bias, four dimensions were used: generation of the randomization sequence; allocation secrecy; blinding; assessment of incomplete results data. For each dimension, three response options were offered: yes (low risk of bias), when the dimension was correctly performed and reported; no (high risk of bias), when the author did not execute the dimension, did not report the method, or reported an invalid method; uncertain risk (uncertain risk of bias) when the method employed or the report raised doubts. These items, when appropriately conducted, are important in assuring the internal validity of the RCT ${ }^{16}$.

The Qualis database was considered to be a results variable, obtained from the site http://Qualis.capes.gov.br. A system of eight strata was used, divided into A1, A2, B1, $\mathrm{B} 2, \mathrm{~B} 3, \mathrm{~B} 4, \mathrm{~B} 5$, and $\mathrm{C}$, given that $\mathrm{A} 1$ represents the maximum weight, while $C$ represents the minimum weight ${ }^{3}$.

The statistical analyses were carried out using the SPSS 17 statistical package for Windows. To verify the association between the ordinal variables of three or more categories, the Kruskal-Wallis statistical test was used. To verify the correlation among the Qualis database, the hierarchy of evidence, and the journal, the Spearman's rho test was used. To verify the prediction capacity of the dependent variable, the Qualis database, based on independent variables (control of risk of bias) was used. To determine the size of the impact of the independent variable on the dependent variable, to order the relative importance of the independent variables, and to assess the interaction of the effects, an ordinal regression was used. The significance level used in the tests was $5 \%($ alfa $=0.05)$, which were considered statistically significant when $\mathrm{p}<0.05$.

This study was analyzed and approved by the Research Ethics Committee from the Paulista School of Medicine at UNIFESP, under the registration number 1891/06.

\section{RESULTS}

Of the total number of studies assessed $(4,879)$, a Qualis classification could be found for 3,961 (81.18\%) studies, as compared to none for 918 studies (18.81\%). The frequency distribution of articles by Qualis hierarchy indicates that grading was more frequent with Qualis B4 $1.754(44,30 \%)$ articles, followed by B3 $1.115(28.10 \%)$ and B1 in 627 $(15.80 \%)$ articles. We can not find journal articles Qualis A1 and A2, as well as Qualis C. 
Table 1 - Qualis classification according to the hierarchy of evidence for the assessed studies.

\begin{tabular}{|c|c|c|c|c|c|c|c|c|}
\hline \multicolumn{9}{|c|}{ Qualis } \\
\hline Hierarchy of evidence & Statistics & B5 & B4 & B3 & B2 & B1 & Total & Kendau-tau-c \\
\hline \multirow[t]{2}{*}{ Lab } & Count & 53 & 602 & 264 & 134 & 416 & 1469 & $<0,000$ \\
\hline & $\%$ of Total & $1.30 \%$ & $15.20 \%$ & $6.70 \%$ & $3.40 \%$ & $10.50 \%$ & $37.10 \%$ & \\
\hline \multirow[t]{2}{*}{$N R, R C$} & Count & 119 & 692 & 473 & 3 & 64 & 1351 & \\
\hline & $\%$ of Total & $3.00 \%$ & $17.50 \%$ & $12.10 \%$ & $0.10 \%$ & $1.60 \%$ & $34.20 \%$ & \\
\hline \multirow[t]{2}{*}{ Trans } & Count & 64 & 382 & 271 & 57 & 74 & 848 & \\
\hline & $\%$ of Total & $1.60 \%$ & $9.60 \%$ & $6.80 \%$ & $1.40 \%$ & $1.90 \%$ & $21.40 \%$ & \\
\hline \multirow[t]{2}{*}{$\mathrm{CC}$} & Count & 0 & 6 & 6 & 0 & 2 & 14 & \\
\hline & $\%$ of Total & $0.00 \%$ & $0.20 \%$ & $0.20 \%$ & $0.00 \%$ & $0.10 \%$ & $0.40 \%$ & \\
\hline \multirow[t]{2}{*}{ Cohort } & Count & 2 & 10 & 10 & 2 & 7 & 31 & \\
\hline & $\%$ of Total & $0.10 \%$ & $0.30 \%$ & $0.30 \%$ & $0.10 \%$ & $0.20 \%$ & $0.80 \%$ & \\
\hline \multirow[t]{2}{*}{$\mathrm{CCT}$} & Count & 8 & 44 & 63 & 5 & 43 & 163 & \\
\hline & $\%$ of Total & $0.20 \%$ & $1.10 \%$ & $1.60 \%$ & $0.10 \%$ & $1.10 \%$ & $410 \%$ & \\
\hline \multirow[t]{2}{*}{ RCT } & Count & 5 & 16 & 25 & 12 & 18 & 76 & \\
\hline & $\%$ of Total & $0.10 \%$ & $0.40 \%$ & $0.60 \%$ & $0.30 \%$ & $0.50 \%$ & $1.90 \%$ & \\
\hline \multirow[t]{2}{*}{ SR } & Count & 0 & 2 & 3 & 1 & 3 & 9 & \\
\hline & $\%$ of Total & $0.00 \%$ & $0.10 \%$ & $0.10 \%$ & $0.00 \%$ & $0.10 \%$ & $0.20 \%$ & \\
\hline \multirow[t]{2}{*}{ Total } & Count & 251 & 1754 & 1115 & 214 & 627 & 3961 & \\
\hline & $\%$ of Total & $6.30 \%$ & $44.30 \%$ & $28.10 \%$ & $5.40 \%$ & $15.80 \%$ & $100.00 \%$ & \\
\hline
\end{tabular}

Legends: Lab (Laboratory studies-in vitro, animal research), CR (Case reports/case series), Trans (cross-sectional/descriptive studies), CC (case control studies), Cohort (cohort studies), CCT (non-randomized controlled clinical trials), RCT (randomized controlled trials), SR (systematic revisions)

Table 1 presents the distribution of study types according to the Qualis database qualification and results from the Kendau-tau rank coefficient.

Overall, the study types were distributed amongst the Qualis categories, with emphasis only on the laboratory studies that dominated the B4 and B1 groups. The narrative research (NR) were most frequent in the B4 $(47.50 \%)$ and B3 $(37.00 \%)$ categories. This followed the same standard as the case reports (CR) with $55.30 \%$ in the B4 category and $32.80 \%$ in the B3 category. Case control and cohort studies were quite infrequent and were published primarily in B4 and B3 journals. Studies with a high level of evidence (CCT, RCT, and SR) were more common in the B3 and B1 categories. The distribution of the study types through the Qualis database classification were tested by Kendau-tau-c, the results of which indicated a significant difference (Valor $\mathrm{p}<0.000)$.

Table 2 presents the bivariate correlation coefficients for the journal, Qualis, and the hierarchy of evidence.

The journal in which the article is published presents a moderate and significant, positive correlation with the Qualis database, given that the proportion of the common variation between the two variables was of $56 \%$. One very weak, yet significant correlation could be observed between the hierarchy of evidence and the Qualis; the proportion of common variation between the two variables was of $7 \%$. Qualis presented a negative and very weak, although significant, correlation with the hierarchy of evidence. The proportion of common variation between the two variables was of $9.7 \%$.

Table 3 presents the strength of relation between the dimensions of risk of bias and the Qualis classification.

To verify if there was in fact a relation between the dimensions of risk of bias and the Qualis classification, the Spearman rho correlation test was used. Only the generation of allocation and blinding presented strong moderate, positive, and significant relations. The Qualis classification was not significantly related to any dimension of risk of bias. In other words, valid studies, with a low risk of bias, are not correlated with the highest levels of the Qualis database.

Table 4 presents the results of an ordinal regression to assess the relation between Qualis and the dimensions of the risk of bias.

As could be observed, none of the dimensions of risk of bias were significantly associated with the Qualis classification. That is, valid studies with a greater control of the items of risk of bias proved not to be associated with better Qualis classifications.

\section{DISCUSSION}

One of the limitations of this study was evaluate a single area of knowledge, dentistry, and the Qualis database only

Table 2 - Spearman's correlation among the journals, Qualis database and hierarchy of evidence.

\begin{tabular}{|c|c|c|c|c|}
\hline Spearman's rho & Statistics & Journal & Qualis & Hierarchy of evidence \\
\hline \multirow[t]{3}{*}{ Journal } & Correlation Coefficient & 1.000 & $-0.563^{* *}$ & $0.077^{* *}$ \\
\hline & Sig. (2-sides) & & $<0.000$ & $<0.000$ \\
\hline & $\mathrm{N}$ & 4879 & 4191 & 4582 \\
\hline \multirow[t]{3}{*}{ Qualis } & Correlation Coefficient & $-0.563^{* *}$ & 1.000 & $-0.097^{\star *}$ \\
\hline & Sig. (2-sides) & $<0.000$ & & $<0.000$ \\
\hline & $\mathrm{N}$ & 4191 & 4191 & 3961 \\
\hline \multirow[t]{3}{*}{ Hierarchy of evidence } & Correlation Coefficient & $0.077^{* *}$ & $-0.097^{* *}$ & 1.000 \\
\hline & Sig. (2-sides) & $<0.000$ & $<0.000$ & \\
\hline & $\mathrm{N}$ & 4582 & 3961 & 4582 \\
\hline
\end{tabular}


Table 3 - Spearman's rho non-parametric bivariate correlation between the dimensions of risk of bias and the Qualis classification database.

\begin{tabular}{|c|c|c|c|c|c|c|}
\hline \multirow[b]{2}{*}{ Variables } & \multirow[b]{2}{*}{ Spearman's rho } & \multicolumn{2}{|c|}{ Generation } & \multirow[b]{2}{*}{ Blinding } & \multirow[b]{2}{*}{ Incomplete Results } & \multirow[b]{2}{*}{ Qualis } \\
\hline & & Allocation & Secrecy & & & \\
\hline \multirow[t]{3}{*}{ Generation of Allocation } & Coefficients & 1.000 & 0.073 & $0.342^{*}$ & 0.159 & 0.079 \\
\hline & Sig. (2-lados) & . & 0.621 & 0.016 & 0.274 & 0.591 \\
\hline & $\mathrm{N}$ & 49 & 49 & 49 & 49 & 49 \\
\hline \multirow[t]{3}{*}{ Allocation secrecy } & Coefficients & 0.073 & 1.000 & 0.124 & 0.244 & -0.011 \\
\hline & Sig. (2-lados) & 0.621 & . & 0.394 & 0.091 & 0.942 \\
\hline & $\mathrm{N}$ & 49 & 49 & 49 & 49 & 49 \\
\hline \multirow[t]{3}{*}{ Blinding } & Coefficients & $0.342^{*}$ & 0.124 & 1.000 & 0.205 & 0.157 \\
\hline & Sig. (2-lados) & 0.016 & 0.394 & . & 0.157 & 0.281 \\
\hline & $\mathrm{N}$ & 49 & 49 & 49 & 49 & 49 \\
\hline \multirow[t]{3}{*}{ Incomplete results data } & Coefficients & 0.159 & 0.244 & 0.205 & 1.000 & 0.071 \\
\hline & Sig. (2-lados) & 0.274 & 0.091 & 0.157 & . & 0.627 \\
\hline & $\mathrm{N}$ & 49 & 49 & 49 & 49 & 49 \\
\hline \multirow[t]{3}{*}{ Qualis } & Coefficients & 0.079 & -0.011 & 0.157 & 0.071 & 1.000 \\
\hline & Sig. (2-lados) & 0.591 & 0.942 & 0.281 & 0.627 & . \\
\hline & $\mathrm{N}$ & 49 & 49 & 49 & 49 & 49 \\
\hline
\end{tabular}

with open access articles indexed in LILACS database. These limitations indicate that findings of this study should be considered very carefully for other areas of knowledge. On the other side if Qualis provides a valid measure of quality of scientific production, and the database and area presents a low level of hierarchy and high risk of bias, this outcome should be well demonstrated by strong correlation with the lowest levels of hierarchy in Qualis database. What happened is that the relationship was random among Qualis are the two variables tested. That is, the theory of quality of scientific production that sustains the measurement proposed by Qualis database is not valid for measuring perhaps the two most important dimensions of quality of scientific production: the strength of scientific evidence and studies validity

What is noteworthy is the predominance of studies with a low level of evidence (in vitro studies, animal studies, narrative reviews, cross-sectional studies, case reports, or case series). Furthermore, studies with higher levels of evidence, such as RCTs and SR, represented only $1.94 \%$ of the articles listed in LILACS. Because of the study type, the RCT is the only one able to minimize any major biases that could distort the outcomes of interventions. RCTs with a low risk of bias provide information with greater validity, when compared to other types of studies, and are the main source of primary studies for SR (systematic review) in the literature $^{17}$. A similar distribution of study designs was also demonstrated in previous studies. In assessing Brazilian dentistry journals, Leles ${ }^{18}$ found that designs with a greater volume of publication were in vitro research, representing $28 \%$ of the examined articles. Oliveira ${ }^{19}$ assessed 5,453 articles on dentistry published between 1993 and 2003 and found that only $6.44 \%$ were RCT or CCT (Clinical controlled trial), while four $(0.07 \%)$ were SR.

Proportionally, the studies published in journals with better Qualis classification were SR, followed by laboratory studies, CCT and RCT. Case study reports and NR (narrative review) were published in journals with lower Qualis classifications in Categories B4 and B5. In the worst Qualis category, B5, NR, and cross-sectional studies were

Table 4 - Ordinal regression considering the Qualis classification as a dependent variable and the dimensions of risk of bias as independent variables for 50 potentially RCT studies indexed in the LILACS database from 2002 to 2007.

\begin{tabular}{|c|c|c|c|c|c|c|c|c|}
\hline & & \multirow[b]{2}{*}{ Estimate } & \multirow[b]{2}{*}{ Standard Error } & \multirow[b]{2}{*}{ Wald } & \multirow[b]{2}{*}{ df } & \multirow[b]{2}{*}{ Sig. } & \multicolumn{2}{|c|}{ Confidence Interval $95 \%$} \\
\hline & & & & & & & Inferior & Superior \\
\hline \multirow[t]{4}{*}{ Limit } & [Qualis = 1] & -4.413 & 1.335 & 10.93 & 1 & 0.001 & -7.029 & -1.797 \\
\hline & [Qualis = 2] & -1.711 & 0.934 & 3.352 & 1 & 0.067 & -3.542 & 0.121 \\
\hline & [Qualis = 3] & -0.781 & 0.907 & 0.742 & 1 & 0.389 & -2.559 & 0.996 \\
\hline & [Qualis = 4] & 0.208 & 0.9 & 0.053 & 1 & 0.817 & -1.556 & $\mathrm{z}$ \\
\hline \multirow[t]{12}{*}{ Position } & [Generation = 0] & -0.212 & 0.811 & 0.068 & 1 & 0.794 & -1.802 & 1.378 \\
\hline & {$[$ Generation $=1]$} & 19.497 & 0 & . & 1 & . & 19.497 & 19.497 \\
\hline & [Generation = 2] & $0^{a}$ & . & . & 0 & . & . & . \\
\hline & {$[$ Secrecy = 0] } & 0.163 & 0.841 & 0.038 & 1 & 0.846 & -1.484 & 1.811 \\
\hline & {$[$ Secrecy = 1] } & -0.679 & 1.347 & 0.254 & 1 & 0.614 & -3.319 & 1.962 \\
\hline & {$[$ Secrecy = 2] } & $0^{a}$ & . & . & 0 & . & . & . \\
\hline & [Blinding = 0] & -0.318 & 0.617 & 0.265 & 1 & 0.607 & -1.528 & 0.892 \\
\hline & [Blinding = 1] & 0.823 & 0.941 & 0.766 & 1 & 0.381 & -1.02 & 2.667 \\
\hline & [Blinding $=2]$ & $0^{a}$ & . & . & 0 & . & . & . \\
\hline & [Incomplete $=0$ ] & 0.221 & 0.907 & 0.059 & 1 & 0.807 & -1.557 & 1.999 \\
\hline & {$[$ Incomplete $=1]$} & -0.642 & 0.679 & 0.894 & 1 & 0.344 & -1.972 & 0.689 \\
\hline & [Incomplete $=2]$ & $0^{a}$ & . & . & 0 & . & . & . \\
\hline
\end{tabular}

Legends: df- degree of freedom; Sig. Significance 
the most frequent types of articles. In terms of frequency, in vitro and animal studies with low level of evidence were predominant in the B2 category, accounting for $66.3 \%$ of all articles in this class. Receiving a high Qualis classification, but without receiving a high level in the hierarchy of evidence, these studies contribute to the distribution of the hierarchy of evidence for Qualis classification, presenting a nonlinear relationship with a U-shaped distribution curve in which studies with a low level of evidence receive high Qualis classifications.

The association between Qualis and journals was strong and significant, confirming that each journal represents a stratified sample of the field of knowledge and not the methodological rigor of the articles published within them. As a result, studies with a low level of evidence and a high risk of bias can receive excellent Qualis classifications if published in journals with a high Qualis level ${ }^{21}$.

These findings provide empirical evidence which proves that there is no association between Qualis classification and the hierarchy of evidence and the validity of scientific studies published in the dentistry field. The practical consequences of this finding is that the Qualis base could represent a policy that encourages and supports distortions in scientific production in the area, in which post-graduate programs focused on in vitro or animal studies could be as well or better assessed and funded than programs focused on clinical trials that produce support for clinical decision-making.

Qualis stratification aims to hierarchize the quality of publications, but quality is a complex construct and must be distinguished from the validity of the studies. Quality suggests that the author of one study conducted a survey according to the highest standards of methodological rigor. However, even high-quality studies may present a high risk of bias due to limitations imposed by the type of design used in the research ${ }^{9}$. For example, in some situations, it is impossible to concealment allocation research groups, though the remainder of the study maintains high quality standards. The lack of concealment in the allocation produces a study with a high risk of bias ${ }^{22}$

Publication quality may result in a series of markers, such as the number of citations, level of indexing in the database, approval by an ethics committee, publication in a peerreviewed journal, bibliographic standards, the performance of previous sample calculations, or reporting studies in accordance with standards such as CONSORT. However, these quality markers have no direct implication on the strength of the evidence or risk of bias in the studies ${ }^{22}$. The results of a main component analysis of 39 quality markers used to hierarchize academic production, including the impact factor, indicated that the concept of scientific impact is a multidimensional construct that cannot be correctly measured by any single indicator, although some measures are more suitable than others. The number of citations used as impact factors is not positioned at the core of this construct, but rather on its margin and, therefore, should be used with caution ${ }^{24}$.

The results of this study show that the hierarchy level of the scientific evidence classified by type of research design, as well as by the validity of studies according to the bias control level, are not correlated or associated with Qualis stratification, which aims to measure the quality of scientific publications in journals indexed in this base, and is based on the impact factor and the indexing hierarchy in databases.
Since its introduction, many articles have been published pointing out the deficiencies in the Qualis assessment. Axt ${ }^{25}$, for example, suggested that this form of assessment induced a homogenous, individualistic thought and exclusionary competition among researchers. He criticized the emphasis of the model in its international position, believing that education and public health, as local and regional-oriented issues, could not be assessed by this model, due to Qualis's inability to assess interdisciplinary productions. When consulting a group of journal editors in psychology, Costa $^{6}$ observed that the main criticism of the Qualis assessment concerned the lack of qualitative assessment of the journals and the content of the articles. Jacon ${ }^{26}$ showed that the Qualis classification of journals did not necessarily induce the researcher to effectively use the better classified journals. In psychology, a survey of journal citations in theses and dissertations showed a greater use of articles from Qualis B journals as compared to Qualis A.

Rocha-e-Silva ${ }^{27}$ highlighted that, due to the new Qualis classification, relatively trivial contributions in some medical "subject categories" merited Qualis A, whereas contributions with high scientific value in other "subject categories" have a very remote chance of reaching that level. The results of this study confirm that the hierarchy of scientific evidence and the internal validity of studies did not influence their Qualis classification. Therefore, it is not considered to be a predictor of the scientific quality of the publications.

The internal validity of studies due to the low risk of bias and the strength of evidence resulting from the type of research design are essential requirements for establishing reliable conclusions regarding the effectiveness both of clinical interventions as well as in public health. Encouraging research studies with a low validity may result in serious consequences for the population and an important loss of opportunity to properly allocate limited resources. The strength of evidence produced by a body of valid studies and high hierarchy of evidence represents the most reliable source for supporting decisions. This should therefore be more valued by the indicators used to hierarchize scientific production and guide those institutions that support and promote research.

\section{REFERENCES}

1. Costa ALF, Yamamoto $\mathrm{OH}$. Publicação e avaliação de periódicos científicos: paradoxos da avaliação Qualis de psicologia. Psicologia em Estudo, Maringá, v. 13, n. 1, p. 13-24, jan./mar. 2008.

2. Lucena AR. Tibúrcio Qualis periodical: view of an academic on medical graduation. Revista da Associação Médica Brasileira. 2009. 55:247-8, doi: 10.1590/S0104-42302009000300011.

3. Tourinho EZ, Bastos AVB. Qualis de periódicos 2008. XII Simpósio da ANPEPP.

4. Dellavalle RL, Schilling M. Rodriguez H. Van de Sompel, Bollen J. Refining dermatology journal impact factors using PageRank. J Am Acad Dermatol. 2007;57:116-9, doi: 10.1016/j.jaad.2007.03.005.

5. Miguel A, Martí-Bonmatí L. Self-citation: comparison between Radiología, European Radiology and Radiology for 1997-1998. Eur Radiol. 2002;12:248-52, doi: 10.1007/s003300100894.

6. Costa ALF. Publicação e avaliação de periódicos científicos: paradoxos da classificação Qualis em Psicologia. PhD diss, Universidade Federal do Rio Grande do Norte, 2006.

7. Kryzanowski R, Krieger E, Duarte F. Programa de apoio às revistas científicas para a FAPESP. Ciência da informação. 1991;20(2).

8. Castro RCF, Ferreira MCG, Vidili AL. Periódicos latino-americanos: avaliação das características formais e sua relação com a qualidade científica. Ciência da Informação 25, no. 3(1996).

9. Higgins JPT, Green S. Cochrane Handbook for Systematic Reviews of Interventions Version 5.0.1 [updated September 2008]. The Cochrane Collaboration, 2008. Available from www.cochrane-handbook.org. 
10. Grégoire G, Derderian F, Le Lorier J. Selecting the language of the publications included in a meta-analysis: is there a Tower of Babel bias? J Clin Epidemiol. 1995;48:159-63, doi: 10.1016/0895-4356(94)00098-B.

11. Clark OA, Castro AA. Searching the Literatura Latino Americana e do Caribe em Ciências da Saúde (Lilacs) database improves systematic reviews. Int J Epidemiol. 2002;31:112-4.

12. Manriquez JJ. Searching the LILACS database could improve systematic reviews in dermatology. Arch Dermatol. 2009;145:947-8, doi: 10.1001/ archdermatol.2009.153.

13. Freitas AE, Herbert RD, Latimer J, Ferreira PH. Searching the Lilacs database for Portuguese- and Spanish-language randomized trials in physiotherapy was difficult. J Clin Epidemiol 58, no. 3, 2005:233-7, doi: 10.1016/j.jclinepi.2004.06.014.

14. Rothman KJ, Greenland S. Modern epidemiology. 2nd ed. Lippincott Williams \& Wilkins, Philadelphia, 1998

15. Phillips B, Chris B, Sackett D, Badenoch D, Straus S, Haynes B, Dawes M. Since november 1998. Updated by jeremy howick march 2009 (http:// www.cebm.net).

16. Higgins JP, White IR, Wood AM. Imputation methods for missing outcome data in meta-analysis of clinical trials. Clin Trials. 2008;5:225-39, doi: $10.1177 / 1740774508091600$.

17. Sackett DL. Why randomized controlled trials fail but needn't: 1 . Failure to gain "coal-face" commitment and to use the uncertainty principle. CMAJ. 2000;162:1311-4.

18. Leles CR, Rocha SS, Simões PA, Compagnoni MA. Ta1a de publicação, na forma de artigos completos, de resumos apresentados em evento científico de pesquisa odontológica. Revista de Odontologia da UNESP 2006;35:141-7.

19. Oliveira G, Oliveira E, Leles C. Tipos de delineamento de pesquisa de estudos publicados em periódicos odontológicos brasileiros. Revista Odonto Ciência 2007; Porto Alegre 22, 55.

20. Patsopoulos NA, Analatos AA, Ioannidis JP. Relative citation impact of various study designs in the health sciences. JAMA. 2005;293:2362-6, doi: 10.1001/jama.293.19.2362.

21. Seglen PO. Why the impact factor of journals should not be used for evaluating research. BMJ. 1997;314:498-502.

22. Pildal J, Hróbjartsson A, Jørgensen KJ, Hilden J, Altman DG, Gøtzsche PC. Impact of allocation concealment on conclusions drawn from metaanalyses of randomized trials. Int J Epidemiol. 2007;36:847-57. Epub 2007 May 21.

23. Moher D, Dulberg CS, Wells GA. Statistical power, sample size, and their reporting in randomized controlled trials. Journal of the American Medical Association. 1994272: 122-124, doi: 10.1001/jama.272.2.122.

24. Bollen J, Van de Sompel H, Hagberg A, Chute R. A Principal Component Analysis of 39 Scientific Impact Measures. PLoS ONE. 2009;4: e6022doi: 10.1371/journal.pone.0006022., doi: 10.1371/journal.pone.0006022

25. Axt M. O pesquisador frente à avaliação na pós-graduação: em pauta novos modos de subjetivação. Psicol. Soc. Porto Alegre 16, no. 1(2004): 69-85.

26. Jacon M. Base Qualis e a indução do uso de periódicos da área de Psicologia. 2007.

27. Rocha e Silva M. O novo Qualis, ou a tragédia anunciada. Clinics. 2009; 64(1):1-4 